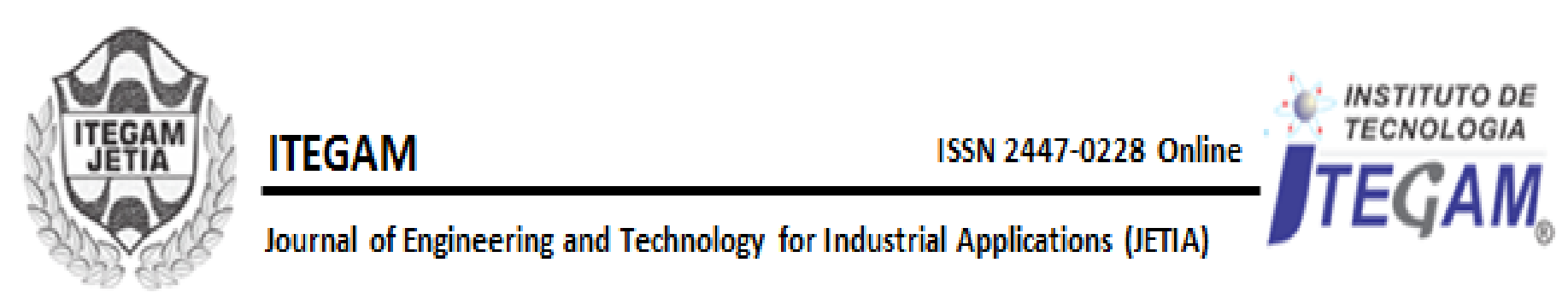

\title{
Treatment and reuse of water by decanting in concrete industries
}

\author{
Adryan Moraes Corrêa ${ }^{1}$, Bruna Almeida Alves ${ }^{1}$, Monik Érica Silva de Souza ${ }^{1}$ \\ ${ }^{1.2}$ Centro Universitário do Norte (UNINORTE). Av. Joaquim Nabuco, 1469, Centro. Manaus-Amazonas-Brasil. \\ (hellodry@hotmail.com,bruna.alves@supermix.com.br,monik.erica_adm@hotmail.com,jandecycabral@hotmail.com)
}

\begin{abstract}
The process of treatment and water reuse is gaining ground especially in large urban centers, where shortages is high investment and operating costs for collection and distribution of water over great distances. This article shows how industries concrete perform the treatment process and reuse the water used in its production. The purpose of this article is to educate the industry to treat and reuse the water used in its production by decanting, a viable resource and widely adopted by businesses today. The methods and techniques used in the field research were: document analysis, interviews and direct observation. The results consisted of conscious consumption of water, the most stringent controls the means employed in its treatment and reuse.
\end{abstract}

Key-words: Treatment, Reuse, Process, Production, Consumption, Control.

\section{Tratamento de água e reutilização de decantação em indústrias de concreto}

\section{RESUMO}

O processo de tratamento e reutilização da água está a ganhar terreno, principalmente nos grandes centros urbanos, onde a escassez são os altos custos de investimento e de operação para a recolha e distribuição de água a longas distâncias. Este artigo mostra como indústrias específicas tornar o processo de tratamento e reutilização da água usada na sua produção. O objetivo deste artigo é o de educar a indústria para tratar e reutilizar a água utilizada na sua produção por decantação, um recurso viável e amplamente adotado pelas empresas hoje. Os métodos e técnicas utilizadas na pesquisa de campo foram: análise de documentos, entrevistas e observação direta. Os resultados consistiu na conscientes do consumo de água, controles mais rígidos sobre os meios utilizados no seu tratamento e reutilização.

Palavras-chave: tratamento, reutilização, processo de produção, o consumo, controle.

\section{INTRODUÇÃO}

Neste artigo veremos como se realiza o processo de tratamento e reutilização das águas utilizadas na produção das indústrias de concreto. $\mathrm{O}$ tratamento da água nas indústrias por meio de decantação é um processo de recuperação da qualidade da água utilizada pela indústria. $O$ tratamento da água deve ser orientado por um profissional da área, como um engenheiro químico, engenheiro ambiental, químico ou técnico químico [1].

Com o tratamento e o reuso da água, ocorrem benéficos sociais, ambientais e econômicos isso tudo só ocorre por um processo que é chamado de decantação, que é de grande importância, pois dentro da empresa ele exerce uma importante função [2].

Esta pesquisa caracteriza-se como um estudo de caso, de natureza descritiva e qualitativa. Para [3], "este tipo de pesquisa ocorre quando se registra, analisa e correlaciona fatos ou fenômenos, sem manipulá-los".

Por meio da coleta de dados foi possível observar o resultado da pesquisa e identificar as deficiências no processo de tratamento e reuso da água na empresa, esses dados foram transformados em gráficos para uma melhor compreensão dos dados. De acordo com [4], "A coleta de dados ajuda a analisar ponto a ponto os fatos ou fenômenos que estão ocorrendo em uma organização, 
Adryan Moraes Corrêa, Bruna Almeida Alves, Monik Érica Silva de Souza/ ITEGAM-JETIA Vol.01, Nº 04, pp. 67-75. Dezembro, 2015.

sendo o ponto de partida para a elaboração e execução de um trabalho".

O estudo foi realizado na empresa SUPERMIX CONCRETO S/A, onde foi possível por meio de pesquisa realizada na empresa, constatar deficiências na área de meio ambiente, principalmente na utilização da água que é o principal insumo utilizado pela empresa. A utilização da água requer um planejamento avançado, para garantir sua disponibilidade permanente, o que quer dizer implantar o seu "uso sustentável", de forma que a construção civil é grande consumidora de água e toda nova obra ou reforma usa litros de água para mistura de agregados com o cimento, formando a massa de concreto [5].

\section{REVISÃO BIBLIOGRÁFICA}

\subsection{Reuso de água}

Para [6], "No Brasil apesar da aparente abundância de recursos hídricos, o reuso de água vem conquistando espaço principalmente nos grandes centros urbanos, onde a escassez representa altos investimentos e custos operacionais para captação e adução de águas a grandes distâncias.

Para a aplicação do reuso em processos industriais, deve ser dada uma atenção especial à qualidade das águas em questão e aos efeitos potenciais na saúde dos usuários, nas instalações da indústria: como corrosão, incrustações e deposição de materiais sólidos nas tubulações, tanques e outros equipamentos, além dos efeitos nocivos aos processos produtivos, como alterações da solubilidade de reagentes nas etapas de processamento e alterações das características físicas e químicas dos produtos finais [6].

Afirma [2], “O reuso e a reciclagem da água nas indústrias, passa a se constituir, portanto, ferramentas de gestão fundamentais para a sustentabilidade da produção industrial”. Sobre este assunto afirma o mesmo autor que: o reuso de água para indústria traz muitos benefícios, como os elencados a seguir:

\section{$\checkmark$ Benefícios ambientais:}

- Redução do lançamento de efluentes industriais em cursos d'água, possibilitando melhorar a qualidade das águas interiores das regiões mais industrializadas;

- Redução da captação de águas superficiais e subterrâneas, possibilitando uma situação ecológica mais equilibrada;

- Aumento da disponibilidade de água para usos mais exigentes, como abastecimento público, hospitalar, etc.

\section{$\checkmark$ Benefícios econômicos:}

- Conformidade ambiental em relação a padrões e normas ambientais estabelecidos, possibilitando melhor inserção dos produtos brasileiros nos mercados internacionais;

- Mudanças nos padrões de produção e consumo;

- Redução dos custos de produção;

- Aumento da competitividade do setor;

- Habilitação para receber incentivos e coeficientes redutores dos fatores da cobrança pelo uso da água. $\checkmark$ Benefícios sociais:

- Ampliação da oportunidade de negócios para as empresas fornecedoras de serviços e equipamentos, e em toda a cadeia produtiva;

- Ampliação na geração de empregos diretos e indiretos;

- Melhoria da imagem do setor produtivo junto à sociedade, com reconhecimento de empresas socialmente responsáveis.

\section{II.2 TRATAMENTO DA ÁGUA POR MEIO DE DECANTAÇÃO}

Sobre este assunto afirma [7] que: O tratamento da água nas indústrias pó meio de decantação é um processo de recuperação da qualidade da água utilizada pela indústria. $\mathrm{O}$ tratamento da água deve ser orientado por um profissional da área, como um engenheiro químico, engenheiro ambiental, químico ou técnico químico.

Reforça [7] que "Frequentemente, a água é utilizada pela indústria para diversas finalidades que vão desde a simples limpeza até no resfriamento de processos industriais". Esta água muitas vezes contém metais pesados ou outros produtos tóxicos ao meio ambiente e por isso a água necessita ser recuperada antes de seu lançamento na rede de esgotos ou nas vias fluviais. A água é um elemento fundamental em praticamente todos os setores industriais. Incentivadas por razões econômicas, diversas empresas passaram a conduzir programas de gestão dos seus recursos hídricos, implementando projetos de reuso, redução de perdas e racionalização do uso, obtendo reduções expressivas do consumo de água e dos lançamentos de efluentes ao meio ambiente. A decantação é uma das técnicas mais antigas e simples de remoção de impurezas da água; Resulta da ação da força da gravidade sobre as impurezas facilitando a sedimentação delas no fundo da unidade.

De acordo [7], “A decantação é um método de separação de misturas heterogêneas de dois tipos: líquido + sólido e líquidos imiscíveis. Essa técnica é física, pois se baseia na diferença de densidade entre os componentes da mistura”.

\section{II.3 FUNÇÃO DO DECANTADOR}

Para [7], “A função dos decantadores é permitir que os flocos que já clarificaram a água no floculador se sedimentem”. A saída da água depois de ocorrida a sedimentação é feita junto à superfície, comumente por calhas dispostas, formando desenhos diversos e sobre cujos bordos superiores a água flui, constituindo esses bordos autênticos vertedouros. Líquido e sólido: O primeiro passo é deixar a mistura em repouso, visto que a parte sólida costuma ser a mais densa, com o tempo e com a ação da gravidade, o sólido irá se depositar no fundo do recipiente. Essa parte do processo é chamada de sedimentação. Depois realizamos a decantação, ou seja, a separação cuidadosa da parte líquida que ficou em cima, transferindo-a para outro recipiente. Pode-se fazer isso por meio de uma sifonação, que é a transferência do líquido por meio de um sifão, iniciando-se o fluxo por sucção. 
Para o sistema de Decantação é aplicado em processos de tratamento de efluente, com a finalidade de remoção de partículas sólidas em suspensão através do processo de sedimentação, ou seja, os flocos de sujeira mais pesados do que as águas decantam e se depositam no fundo do decantador. De acordo com [7], $\mathrm{O}$ efluente a ser clarificado é introduzido ao tanque através de sistema de alimentação central, visto que tal sistema permite a alimentação do tanque de decantação de forma constante e uniforme, diminuindo os efeitos de turbulência.

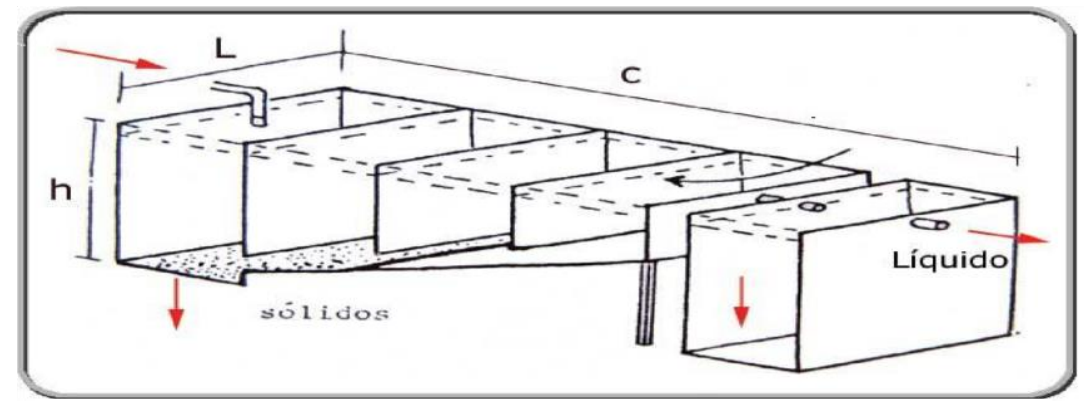

Figura 1 - Processo de um Decantador Convencional.

Fonte: [7].

A retirada do lodo (sólidos que se sedimentam no fundo do Decantador é efetuada através de sistemas de descargas de fundo automáticas ou manuais. A água purificada através da separação é retirada pela parte superior do equipamento, através de "calha coletora" ao tanque de decantação.

\section{II.4 TIPOS DE DECANTADORES}

Segundo [7], "Existem os decantadores clássicos, que podem ser de seção retangular ou circular e os decantadores tubulares, que podem ser de fluxo ascendente ou fluxo horizontal". Os decantadores são tanques onde a velocidade da água, após a floculação, sofre uma diminuição para permitir a deposição dos flocos, geralmente têm formato retangular ou circular". Possuem dispositivos na entrada, previstos para melhor distribuição de água (evitando curtos-circuitos) e dispositivos na saída para evitar arraste de flocos.

Quanto à operação podem ser agrupados:

- $\quad$ Convencionais (clássicos) - recebem a água floculada e precessam apenas a decantação;

- De Contato de Sólidos ou Floco Decantador processam a floculação e decantação no mesmo tanque (manto de lodo entre 10 e $20 \%$ do volume).

- De Fluxo Laminar ou Tubulares - utilizam elementos tubulares ou placas paralelas para direcionar o fluxo.

\section{$\checkmark \quad$ Quanto ao escoamento:}

- Horizontal - A água floculada entra numa extremidade. Escoa no sentido longitudinal em plano horizontal e é coletada na outra extremidade.

- Vertical - A água floculada entra na parte inferior no tanque, escoa no sentido vertical e é coletada na superfície.

\section{MATERIAIS E MÉTODOS}

Esta pesquisa caracteriza-se como um estudo de caso, de natureza descritiva e qualitativa. Para [3], "este tipo de pesquisa ocorre quando se registra, analisa e correlaciona fatos ou fenômenos, sem manipulá-los".

O estudo foi realizado na empresa SUPERMIX CONCRETO S/A, onde foi possível por meio de pesquisa realizada na empresa, constatar deficiências na área de meio ambiente, principalmente na utilização da água que é o principal insumo utilizado pela empresa. A utilização da água requer um planejamento avançado, para garantir sua disponibilidade permanente, o que quer dizer implantar o seu "uso sustentável", de forma que a construção civil é grande consumidora de água e toda nova obra ou reforma usa litros de água para mistura de agregados com o cimento, formando a massa de concreto [5].

Os instrumentos de pesquisa utilizados na pesquisa foram: a análise documental, entrevista e observação direta. Para a pesquisa foram elaborados formulários de pesquisas. Através do formulário de análise documental foi possível coletar documentos como: relatórios, certificações, certidões, comprovantes, atas, estatutos, manuais entre outros, a fim de identificar se a empresa conta com documentação padronizada. Para a entrevista foi elaborado um roteiro com sete perguntas aos três funcionários de níveis hierárquicos diferentes. Um funcionário do nível estratégico, do nível tático e do nível operacional. Na observação direta foi utilizado um formulário de observação direta onde cada integrante pode preencher de acordo com a sua análise pessoal. Segundo [8] "chama-se de instrumento de pesquisa o que é utilizado para a coleta de dados", ou seja, é estabelecido efetivamente o que será utilizado no desenvolvimento do estudo para a obtenção das informações pertinentes ao trabalho. Por meio da coleta de dados foi possível observar o resultado da pesquisa e identificar as 
Adryan Moraes Corrêa, Bruna Almeida Alves, Monik Érica Silva de Souza/ ITEGAM-JETIA Vol.01, Nº 04, pp. 67-75. Dezembro, 2015.

deficiências no processo de tratamento e reuso da água na empresa. De acordo com [4], "A coleta de dados ajuda a analisar ponto a ponto os fatos ou fenômenos que estão ocorrendo em uma organização, sendo o ponto de partida para a elaboração e execução de um trabalho".

\section{RESULTADOS E DISCUSSÕES}

A Supermix Concreto S/A é uma empresa que atua na área de engenharia de concreto, mais especificamente na mistura, transporte e lançamento de concreto usinado em central. Fundada em 1976, em Belo Horizonte, atualmente com capacidade de entrega de mais de 7 milhões de metros cúbicos por ano a partir das mais de 130 filiais espalhadas pelo Brasil e pelo estado da Flórida.

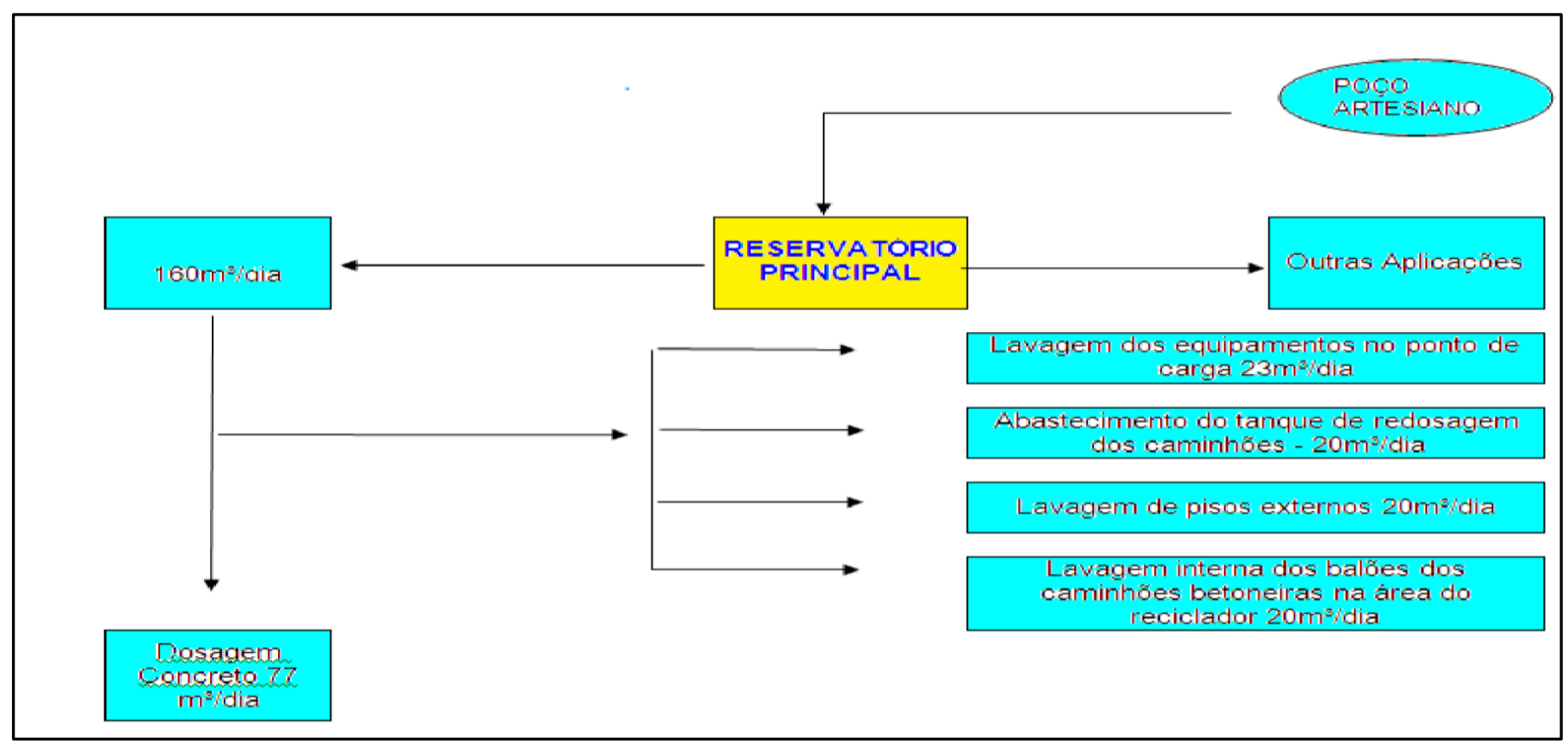

Figura 2 - Demonstração da aplicação da água na central.

Fonte: [7].

\section{IV.1 REAPROVEITAMENTO DA ÁGUA NA CENTRAL DE CONCRETO}

O sistema de reaproveitamento de água, através do processo em funcionamento, proporciona uma economia de $50 \%$ da quantidade de água utilizada na dosagem do concreto. 3.
Isso equivale a $1000 \mathrm{~m}^{3}$ de água por mês, ou seja, a $38 \mathrm{~m}^{3}$ por dia que são economizados, deixando de serem extraídos do poço artesiano para a dosagem do concreto, conforme mostra a Figura

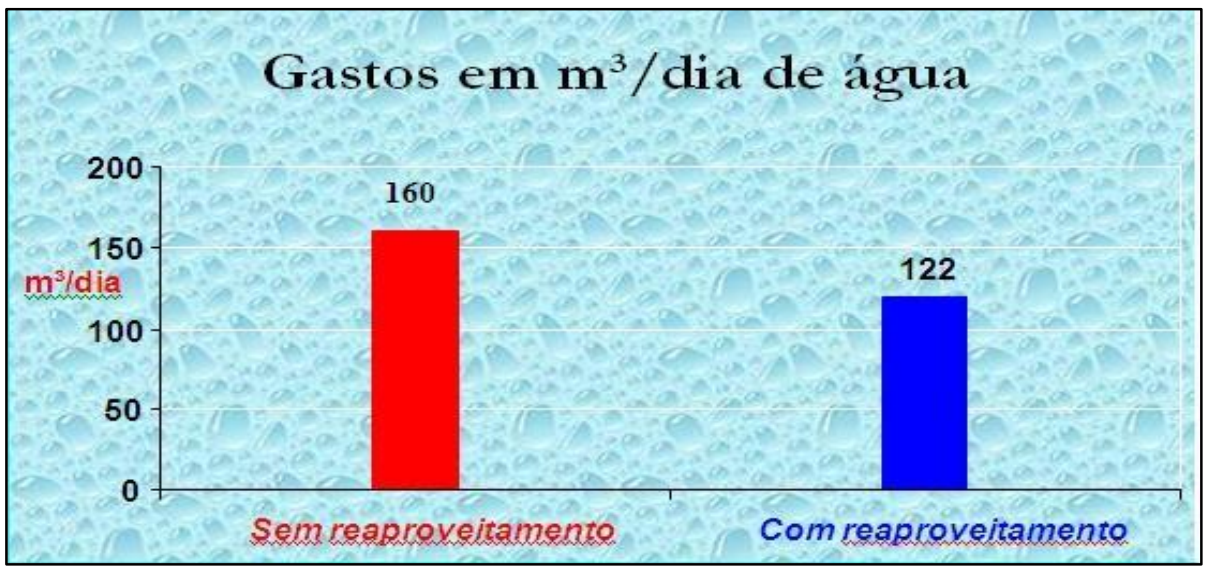

Figura 3 - Aproveitamento da água.

Fonte: [7]. 
Adryan Moraes Corrêa, Bruna Almeida Alves, Monik Érica Silva de Souza/ ITEGAM-JETIA Vol.01, Nº 04, pp. 67-75. Dezembro, 2015.

\section{IV.3 PROCESSO DE UTILIZAÇÃO DA ÁGUA}

A lavagem dos caminhões betoneiras tem como resíduo a água contaminada, que não pode retornar aos rios. Essa lavagem ocorre no bate lastro, onde posteriormente vai para o decantador.
A água do poço artesiano é utilizada inicialmente na dosagem do concreto, onde ocorre a mistura da matéria-prima. A água que cai fora escorre para as canaletas que levam a água até o decantador.

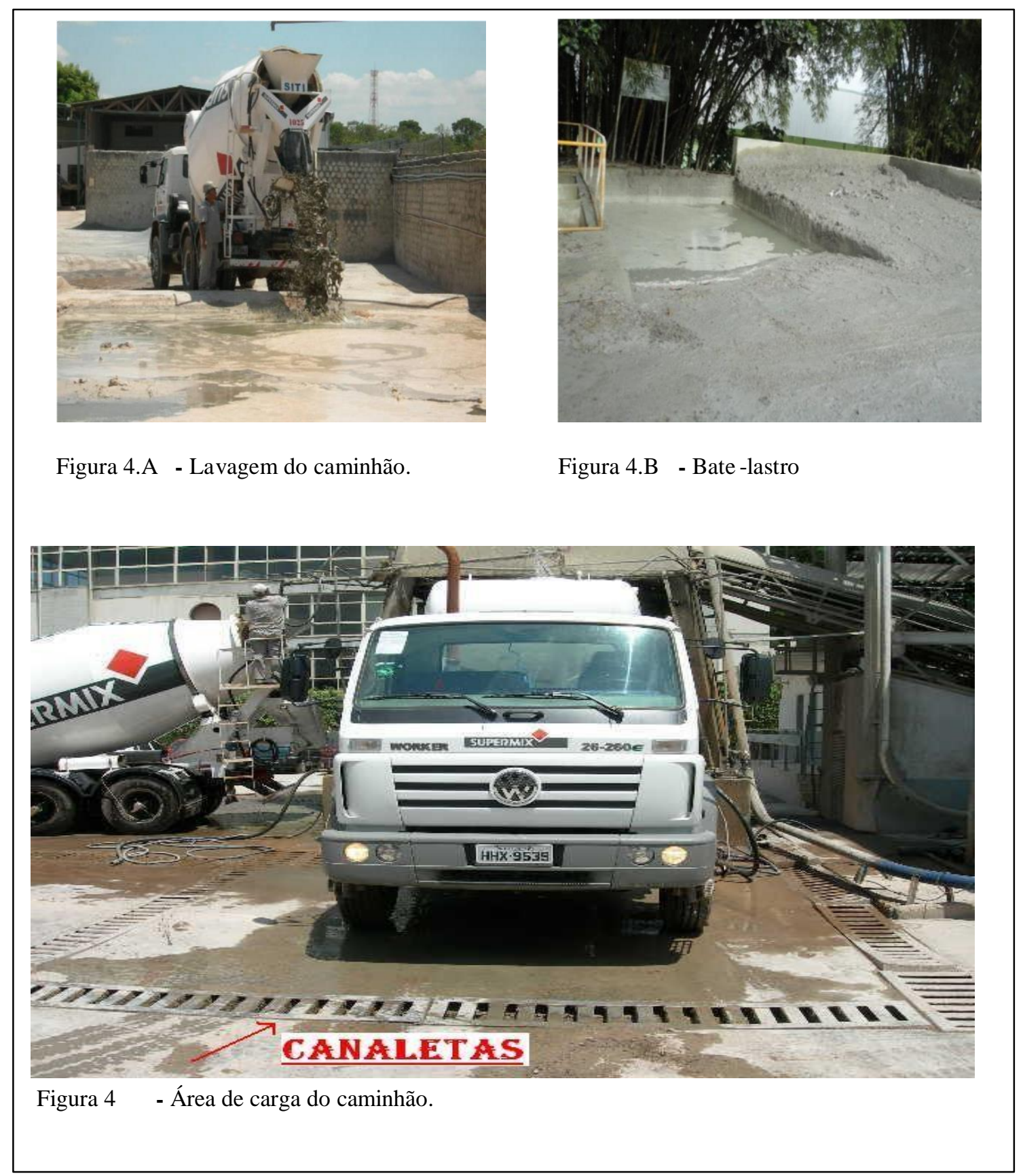

Figura 4 - Processo da utilização da água.

\section{IV.4 PROCESSO DE RECICLAGEM DA ÁGUA}

O processo de reciclagem da água é feita através de decantação, onde a água "com flocos" passa pelo decantador, objetivando a eliminação dos flocos, por decantação.
Esta etapa consiste na separação sólida - líquido, por meio da sedimentação das partículas sólidas. Os tanques de decantação podem ser circulares ou retangulares. Os efluentes fluem vagarosamente através dos decantadores, permitindo que os 
Adryan Moraes Corrêa, Bruna Almeida Alves, Monik Érica Silva de Souza/ ITEGAM-JETIA Vol.01, Nº 04, pp. 67-75. Dezembro, 2015.

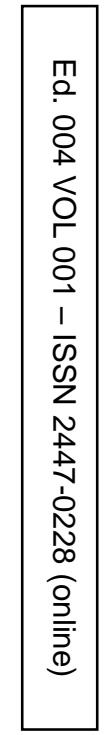

sólidos em suspensão, que apresentam densidade maior do que a

do líquido circundante, sedimentem gradualmente no fundo.

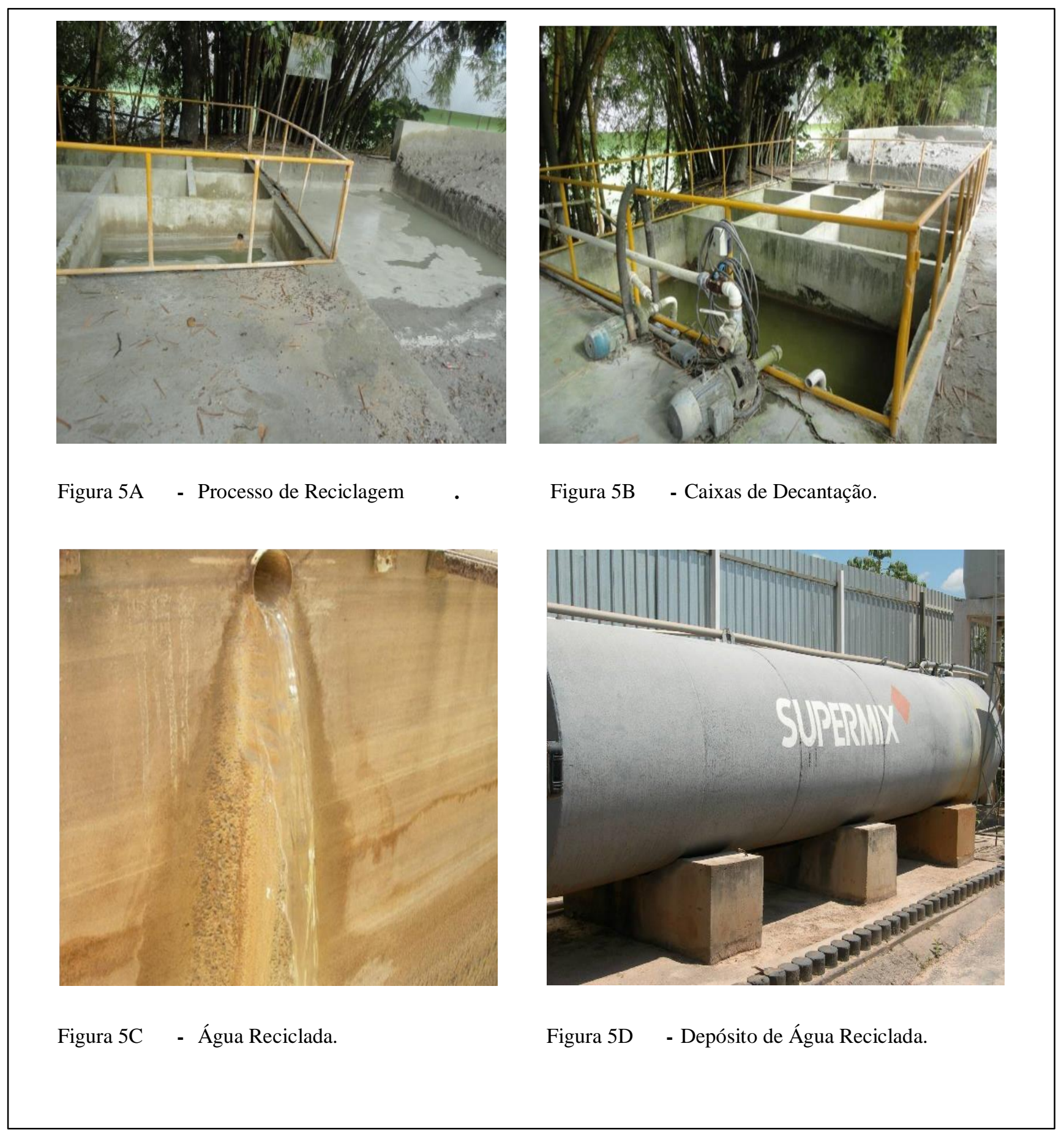

Figura 5 _ Processo reciclagem da água.

A água reciclada é armazenada em um depósito, conforme mostra figura 5D, onde será utilizada posteriormente para redosagem de concreto, lavagem dos caminhões e lavagem do pátio. 


\section{IV.4 PESQUISA SOBRE O TRATAMENTO E O REUSO DA ÁGUA}

Foi realizada uma entrevista com os níveis estratégico, tático e operacional da empresa Supermix Concreto S/A. para apurar o conhecimento dos colaboradores sobre a existência de programas de gestão de economia de água e o interesse nas melhorias dos mesmos, conforme mostram as figuras a seguir:

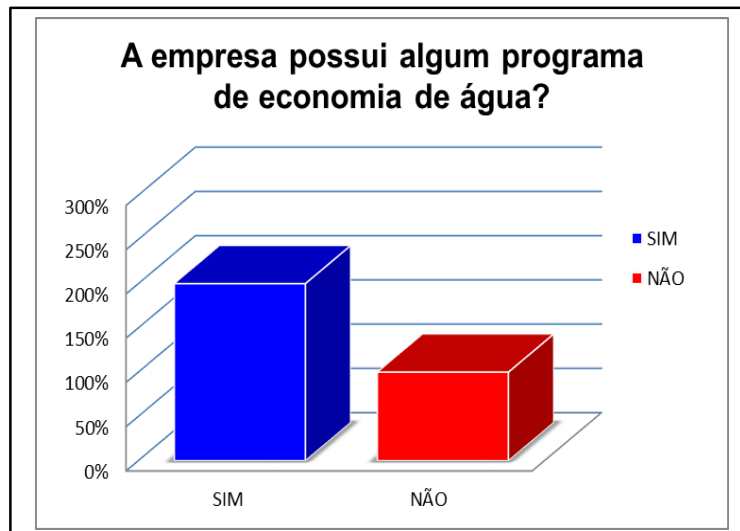

Figura 6.A_ Programa de economia de água.

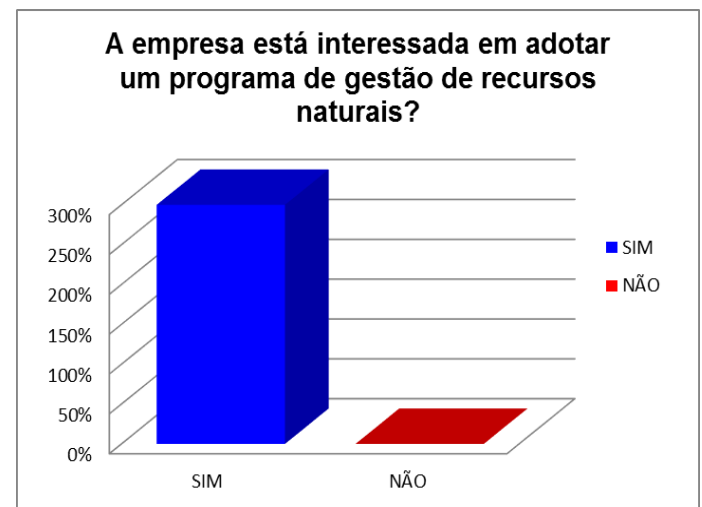

Figura 6.C - Interesse em adotar um programa de gestão de recursos naturais

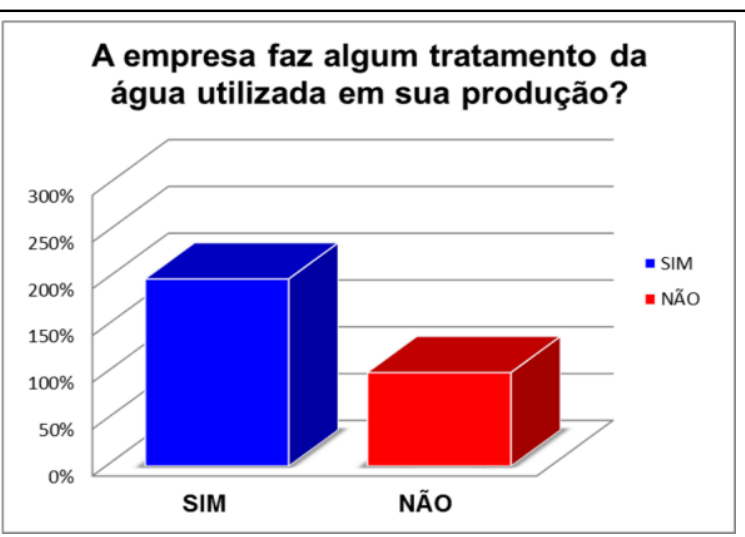

Figura 6.B - Tratamento da água utilizada em produção.

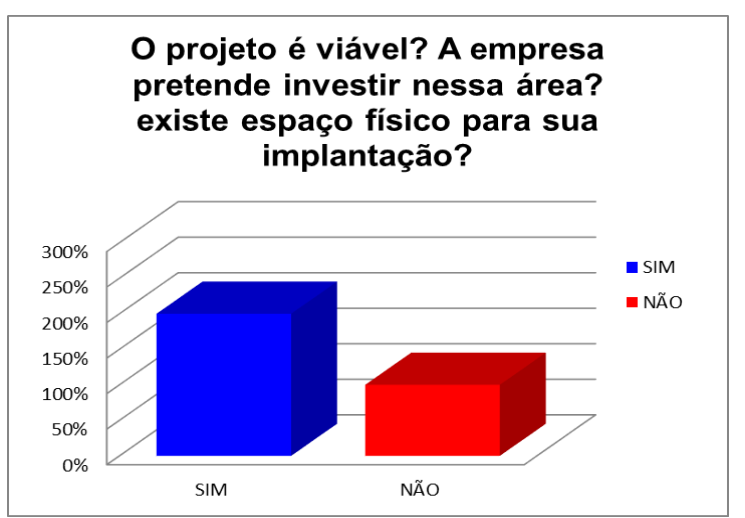

Figura 6.D Viabilidade do projeto para a empresa.

Figura 6 - Pesquisa sobre o tratamento e o reuso da água.

A Figura 6A mostra que apenas o nível estratégico e tático tem o conhecimento que a empresa possui um programa de economia de água. A Figura 6B mostra que todos os níveis tem o conhecimento de que a empresa faz algum tratamento da água utilizada em sua produção, que é o decantador.

A Figura 6C mostra que todos os níveis tem o conhecimento de que a empresa se interessa em adotar uma gestão de recursos naturais.
A Figura 6D - Mostra que somente o nível estratégico e tático acreditam na viabilidade do projeto, o nível operacional acredita que não existe espaço físico na empresa para a implementação do projeto.

$\mathrm{Na}$ pesquisa em campo, também foi aplicado um questionário de observação direta, no qual foi possível coletar informações sobre todos os meios utilizados na empresa para a utilização da água, como mostra o gráfico a seguir: 




Figura 7 - Uso da água.

A Figura 7 mostra que o uso da água nos banheiros é ruim, pois os mesmos precisam de manutenção. Recomenda-se que a empresa adote descargas e torneiras econômicas e faça sempre a sua manutenção. O lava jato, dosador e o decantador estão em um estado regular. O lava jato e os dosadores precisam de manutenção, e o decantador precisa ser ampliado, pois possui tamanho inadequado para a sua demanda. $\mathrm{O}$ tanque é o único meio pelo qual está em bom estado. Sugere-se que a empresa continue fazendo a manutenção do mesmo, visto que ele é uma boa medida de economia de água.

\section{CONCLUSÕES}

Esta pesquisa permitiu a compreensão de como funciona o processo de tratamento e reuso da água por meio de decantação nas indústrias de concreto.

Notou-se que a água é um dos insumos mais utilizados no processo de concretagem, pois é necessária para as reações de hidratação do cimento e como agente que fornece a plasticidade aos componentes da mistura do concreto. Este sistema de reaproveitamento de água, através do processo em funcionamento, proporciona uma economia de $50 \%$ da quantidade de água utilizada em cada dosagem do concreto.

$\mathrm{O}$ processo de reciclagem da água é feita através de decantação, onde a água "com flocos" passa pelo decantador, tendo como objetivo a eliminação dos flocos, por decantação. Esta etapa consiste na separação sólida - líquido, por meio da sedimentação das partículas sólidas. Os tanques de decantação podem ser circulares ou retangulares. Para a elaboração desse artigo foi realizada uma visita técnica a empresa Supermix Concreto S/A, e feita uma pesquisa com os três níveis da empresa: o estratégico, tático e operacional, onde foi possível coletar todos os dados e elaborar os gráficos para uma melhor compreensão dos dados. Por meio da pesquisa foi possível verificar que a água é um elemento fundamental em praticamente todos os setores industriais.

\section{AGRADECIMENTOS}

Agradecemos ao Centro Universitário do Norte (UNINORTE), e a empresa Supemix Concreto S/A, pelo apoio a realização desta pesquisa.

\section{VII.REFERÊNCIAS BIBLIOGRAFICAS}

[1] CINTRA, M. Decantação, Flotação, Filtração e desinfecção. Universidade Federal de Ouro Preto. Minas Gerais: 2012. Monografia. Escola de Minas Departamento de Engenharia Civil - Saneamento Urbano.

[2] MINOWA, C. Água em Ambientes Urbanos: Reuso da Água. São Paulo, 2010. Monografia. Escola Politécnica da Universidade de São Paulo - Departamento de Engenharia Hidráulica.

[3] BERVIAN, P. A., CERVO, A. L. Metodologia Científica. 5. Ed. São Paulo: Prentice hall, 2010.

[4] GIL, Antônio Carlos. Como elaborar projetos de pesquisa. 7. ed. São Paulo: Atlas, 2011.

[5] SALAMA, Fábio. Gestão da água. Vol. 03. Cuiabá: SEBRAE, 2012. 
Adryan Moraes Corrêa, Bruna Almeida Alves, Monik Érica Silva de Souza/ ITEGAM-JETIA Vol.01, Nº 04, pp. 67-75. Dezembro, 2015.

[6] LAVRADOR, J. Contribuição para Entendimento do Reuso Planejado da Água e Algumas Considerações sobre ○ Possibilidades de uso no Brasil. São Paulo, 2012. Dissertação $\lesssim$ de Mestrado. Escola Politécnica da Universidade de São Paulo.

○ [7] SILVA, João. Reciclagem e Reaproveitamento dos [7] SILVA, João. Reciclagem e Reaproveitamento dos Brasília-DF. In: $7^{\circ}$ Prêmio Furna Ouro Azul, Belo Horizonte, 31 de Outubro de 2008.

[8] RUDIO, F. V. Introdução ao projeto de pesquisa científica. 5. Ed. Petrópolis: Vozes, 2011. 